\title{
TEACHING TEAMWORK TO ENGINEERING TECHNOLOGY STUDENTS: THE IMPORTANCE OF SELF-REFLECTION AND ACKNOWLEDGING DIVERSITY IN TEAMS
}

\author{
Jennifer Long, Amin Reza Rajabzadeh, and Allan MacKenzie \\ McMaster University, W. Booth School of Engineering Practice \& Technology \\ longjen@mcmaster.ca, rajab@mcmaster.ca, mackenza@mcmaster.ca
}

\begin{abstract}
In their quest to find work-ready graduates, employers are increasingly prioritizing graduates with socalled transferable skills. These transferable skills include critical thinking and problem-solving skills, communication skills, and the ability to work in diverse teams. With the plethora of engineering education literature on the topic of developing undergraduates' teamwork abilities, there are numerous suggestions and little consensus on the best way to develop these skills in engineering classrooms. This paper adds to this literature and provides an overview of group work workshops for first-year undergraduates. The hope for these workshops was to better equip students for future group work activities by providing them easy-to-remember teamwork tools that were first learned and practiced in low-stakes workshop environments. Following their participation in these workshops, students participated in focus groups and feedback demonstrated an appreciation for these workshops as well as the opportunity to self-reflect on their role as a team member. Further, there appeared to be a shift in the awareness and tolerance of the diversity found among group members, which demonstrates a potential area for further investigation. The authors conclude with a call for more research in order to better understand the role of teamwork as a means for developing tolerance toward diversity among first-year undergraduate students.
\end{abstract}

Keywords: Groupwork, team work, tolerance for diversity, engineering technology, first-year undergraduate education

\section{INTRODUCTION}

There are two, first-year communication courses in the Bachelor of Technology program (B.Tech.) in the W. Booth School of Engineering Practice \& Technology at McMaster University. In the past, the final group report and presentation produced only mediocre results and anecdotal evidence suggested that most student groups faced some form of negative team or group work experience. These anecdotal findings align with research in the field of team and group work among undergraduate students including a recent study about undergraduate engineering students' teamwork [1]. The authors found that
$85 \%$ of participants experienced at least one problem, the most common being a "slacker teammate". While high achieving students were more proactive when dealing with slacker teammates, students often preferred to "do nothing" when confronted with domineering or exclusionary teammates. In conclusion, the authors argued that undergraduates lacked the ability to solve group work problems and called for more training around problem solving skills for undergraduates.

To date, team membership and group work skills have not been overtly taught in B.Tech. (beyond secondary resources made available to students and cursory peer evaluations), despite group work being one of our program level outcomes. In response, a series of workshops were developed to provide first-year students with an overview of team membership and group work best practices. These workshops incorporated self-reflection as a focus, in line with the work by Hirsch and McKenna [2], and were launched in fall 2016. The hope for these workshops was to better equip students for future group work by providing them easy-to-remember tools and accessible resources about working in a group. What the authors found was that first-year students also developed an appreciation for their peers' individual diversity and, through self-reflection activities, developed a deeper level of self-awareness about one's worldview. These secondary outcomes open the conversation as to the importance of learning about interpersonal skills and teamwork early in engineering education where Canadian engineering programs continue to struggle with diversifying both their student body and faculty $[3,4,5,6]$.

In what follows, the authors provide a brief overview of the engineering education literature that seeks to identify best methods for teaching groupwork skills to undergraduates. Next, we provide an overview of the group work workshops. Then, we describe the outcome of focus groups held with students concerning their experiences of the workshop. Finally, the authors conclude with a call for more research to better understand the role of teamwork as a means for developing tolerance of diversity among firstyear undergraduate students. 


\section{LITERATURE REVIEW}

The body of engineering education literature on effective group work practices is robust. Scholars have identified the benefits of group-based learning including its ability to provide "significant gains in academic success, quality of interactions with both classmates and faculty members, and attitudes toward the college [university] experiences" [7]. Leaders in the field have identified numerous best practices when teaching group work or skills for team membership in engineering classrooms.

The following is a list of strategies for instructors seeking to teach undergraduates about teamwork:

1. Institute instructor-formed heterogeneous student groups after class numbers have been stabilized (after the drop and add period) $[8,9$, $10]$.

2. Allow students to self-form into groups to lower the instance of conflict $[7,11]$

3. Provide specific tutoring or guidance toward team and group work best practices $[7,8,9,10$, 11]

4. Articulating clear objectives for group work [9, 10]

5. Form teams of three to five members $[10,11]$

6. Articulate the importance of working in groups at the start of the activity or semester $[10,11]$

7. Engender team coherence and group belonging through ice breaker activities [11]

8. Establish team expectations early in their formation, for example, through group contracts $[10,11]$

9. Identify group or task roles [9]

10. Identify and address group work stress points throughout the semester [7, 8, 10,11]

11. Collect peer ratings or feedback and adjust individual student's grades depending on level of participation $[8,9,10,11]$

12. Facilitate opportunities to collect, anonymize and distribute peer feedback on colleagues' work throughout the semester $[8,9,10,11]$

13. Allow students to 'fire' members who are not pulling their weight or 'quit' $[7,8,11]$

14. Work through conflict using active listening techniques $[8,11]$

While some advice is seen to be contradictory, (for example, see above advice on who should form student groups), scholars agree that meaningful instructor engagement, clear and focused group tasks, and accounting for conflict and its resolution remain key factors of successful undergraduate groupwork instruction.

The groupwork workshops integrated into the B.Tech. program included activities and material meant to provide students with a toolkit when engaging with peers and in groups within academic settings and later in the workplace.
In the next section, the authors provide an overview of the group work workshop design including the subject matter and assessments. We also discuss the importance of learning about teamwork in a low-stakes environment.

\section{GROUP WORK WORKSHOP DESIGN}

The best practices from the Engineering Education literature were used to identify suitable topics for three workshops that were given during regularly scheduled class time. Each workshop was meant to build on the lessons and materials covered in the previous workshop with a culminating activity - in the final week of workshops - with the aim of allowing students to demonstrate the skills they learned in the previous workshops. The following is a brief overview of these workshops and their associated assessments.

\subsection{Workshop Design and Subject Matter}

The first 'group work' workshop took place following nine weeks of more typical undergraduate course structure; that is, students learned material about topics featured in the communications course textbook and examples pulled from industry situations and instructor experiences. Instructors taught this material using lecture-style instruction and in-class active learning activities that were evaluated through various summative assessments.

For the first workshop, students were asked to read Charles Duhigg's article from the New York Times "What Google Learned from Its Quest to Build the Perfect Team" [12]. This departure from the textbook as a reading resource was useful in signalling a departure from the regular course-based material. The workshop content also differed from previous classes due to its prioritization of activity-based experiential learning [13] with far fewer short, interspersed lectures.

In the first workshop week, students were asked to selfreflect on their past experiences as a team member and then asked to reflect on how they like to work in a team using an activity based on Joseph Luft and Harrington Ingham's (1955) Johari Window [14]. These reflections were completed individually and then discussed in the larger group. Following a transitionary activity and short lecture on conflict management techniques, students were then put in small groups and asked to devise strategies for mitigating group conflict. These scenarios included such topics as working with peers who were resistant to group work or working with a dominating team member. These activities were interspersed with short overviews of practical tools for students - tools which built toward their teamwork toolkit - from which they could draw in future group work scenarios. In the above conflict scenarios activity, for example, students learned de-escalation techniques such as "I-statements" or behaviour, consequences, and feelings statements. The final activity of this session focused on practicing active listening. 
This relatively in-depth overview of the first week of workshops provides insight into the teaching and learning approach applied across the three weeks. In brief, the second and third workshops covered topics including: healthy team environments; functioning teams; best practices for team and project management (for example, identifying team norms, making timelines, scheduling meetings, having a communication plan); group roles (and their rotation); decision making strategies; and best meeting practices for generating ideas and completing quality work on time. While there appear to be quite a few topics covered in these remaining in-class workshops, experiential learning activities were devised to address more than one of these topics at a time. Further, the instructor debriefed each activity to highlight best practices outlined in the literature review. Finally, the instructor provided take-home materials for students that underlined these best practices to use as a future resource.

Throughout these workshops, students were asked to reflect on their own experiences and preferences as a team member. The importance of self-reflection as a tool for building awareness through transformative learning is further discussed in section 4 .

\subsection{Workshop Assessment}

To help engender student buy-in and ensure attendance during the final weeks of class, a time when attendance typically falls off, students received $2.5 \%$ toward their final grade for coming to class and taking part in each of the three, 3-hour workshops. In addition to marks associated with the in-class attendance, students were asked to submit three written assignments. These written assignments integrated materials covered in class and involved selfreflection. As an example of these written assignments, students were asked to write and submit answers to the following questions after participating in the first workshop:

1. Describe what kind of team member you think you are.

2. How might your actions and behaviours in groupwork affect other team members and the overall project outcome?

3. What kind of teams work best? Use Charles Duhigg's NY Times magazine article to answer this question.

4. What are your strengths as a team member?

5. What skills do you need to (further) develop for future group situations?

Such exercises were worth a nominal amount $(2.5 \%$ of one's final grade) to encourage their completion at a point in the semester where students were busy juggling competing academic responsibilities. Across the seven communication skills course sections, the rate of completion for this first assignment was $83.3 \%$. While instructors did not provide formative feedback on each of the students' submissions, they did read them and assign a summative grade with general feedback, for example, submissions receiving the highest grade would include the following feedback: Answered all questions, interwove secondary resources expertly, formatting and grammar made for clear and persuasive communication, and no errors found in referencing (in-text $\&$ references section). However, instructors gave detailed feedback to the entire class on these assessments and best practices in selfreflection in the second and third workshops. Considering the placement of these workshops in a course on communication skills, these written assignments also assessed the best practices of written communication.

Altogether, the participation and complementary written assignments associated with these group work workshops culminated to $15 \%$ of students' final grade. The grade allocation was designed to allow students numerous opportunities to take part in these workshops and reward those who participated in self-reflection activities both in-class and by submitting their completed written assignments.

These group work workshops are unique because students learned about the best practices of team membership and group work outside of a significant group assignment which may carry significant grades with it. The focus on obtaining a group work skillset as the sole learning outcome is something not yet discussed in the literature. To date, the authors have not found other studies or examples of such an approach in the Engineering Education literature. As such, these workshops provide a rare opportunity to understand student perspectives about the acquisition of these skills unaffected by their larger group work experiences. As described below, these workshops also provide an opportunity to learn about and understand the role of heterogeneous team members.

\section{CONNECTING DIVERSITY TO TEAMWORK TRAINING}

The goal behind these workshops was to provide students with a teamwork toolkit which they can use in future educational scenarios and further hone when completing their mandatory co-op placement as part of their B.Tech. degree. However, a secondary - although no less important intended learning outcome - was to acknowledge the existence of different learning and collaboration styles within the classroom. Instructors worked to frame this acknowledgement of difference as a benefit rather than something that detracts from productivity and quality of work.

Using Schön's work, Adams, Turns, and Atman argue for an iterative and reactionary (reframing) approach to problem-solving in practice for engineering design [15], the first author developed these workshops with the intention of (further) developing students' skills at reflective practice. In brief, this practitioner approach can be applied to a groupwork context by having students (1) 
react or problem-solve with team members and in team environments, (2) build awareness and develop skills that help work through group conflict, (3) practice flexibility in how one interacts and solves problems when faced with team and project-based issues.

Mann, Gordon, and MacLeod have argued that the ability to reflect is an "essential characteristics for professional competence" [16]. Williams has also argued for the importance of reflection as a learning dimension that is too often undervalued in undergraduate engineering education [17]. Finally, building on the body of pedagogical theory surrounding reflective practice, Hey, Van Pelt, Agogino, and Beckman identified self-reflection as a tool for students to learn and compare their own experiences to those of 'successful practitioners' [18]. These capabilities are not just important during their education but in their journey to become successful professionals.

The first-author, who is also the lead instructor for the first-year communications courses in B.Tech. and is a trained socio-cultural anthropologist, has conducted research, and developed and facilitated training materials on the topic of intercultural communication and diversity in Canadian workplaces. Her experience in designing intercultural competency workshops based on transformational learning was influential in the creation of these group work workshops. These workshops sought to build students' ability to transform their perspective, as advocated by Mezirow [19], which involves the process of becoming critically aware of one's own perspective, of reformulating assumptions to be more inclusive, and to help students deal with "a broader range of experience(s)... [and] be more open to other perspectives". As such, activities were designed to engender knowledge, skills and positive feelings toward difference when encountered in team environments.

In its current form, these workshops provided an opportunity to acknowledge and appreciate 'difference' in relation to one's own identity. According to Neale, different types of diversity can create different kinds of conflict which affect how a team will perform [20]. Neale argued that demographic diversity could create interpersonal conflict, stating "this is the kind of conflict people should fear. People think, I have a different opinion than you. I don't like what you do or how you do it. I don't like you". In their research, Jehn, Northcraft, and Neale [21] found that informational diversity, that is, a person's education, experience, as well as values and goals for the project, produced productive conflict often leading to higher quality output. With the hope of increasing diversity in undergraduate engineering programs, it is important to mitigate these negative outcomes and find ways to prepare our students to work in diverse teams in the classroom and workplace.

Using teamwork preferences to engage and appreciate peers' informational diversity may also engender tolerance toward demographic diversity and is an avenue requiring further exploration in the field of engineering education. Scholars have argued that students should be organized in homogeneous teams according to gender and ethnic identities in order to mitigate isolating experiences for visible minority students in the classroom [8, 11]. These authors implied that students will gain a tolerance for difference (that is, different peers) as they mature - noting that creating heterogeneous groups was appropriate for third and fourth year undergraduates. As with group work skills and self-reflection, these skills must be taught to students overtly to give students sufficient time to understand their own biases, both conscious and unconscious, in the classroom and as future engineering practitioners.

Having acknowledged the role of diversity in this training, the group work workshops did not incorporate any overt material on demographic diversity. However, experiential learning activities incorporated scenarios with diverse identities and instructors debriefed these activities by asking students their opinions on the role of personal identity in relation to team work scenarios. The importance of demographic diversity of team members was a topic covered in the textbook, the reading of which was assigned and assessed through online quizzes and the final exam.

As such, through various activities designed to develop self-awareness of one's own strengths and weaknesses within teams, students were afforded an opportunity to identify their peers' teamwork preferences that overlapped pre-existing social and cultural identities. In this way, preferences for teamwork became a means to align oneself with individuals who one may or may not be perceived as socially and culturally different. Further, the identification of one's own preferences when working in teams provided students another world view, that is, an encompassing picture of reality based on shared cultural assumptions about how the world works [22].

As will be further described in the next section, students identified the benefits of working with different students (as a heterogeneous workforce on a defined project) and acknowledged that their own method of group work, could be particular to themselves. This latter point is important to the process of self-reflection and understanding and accepting the unique position of one's point of view. The importance of these factors is further elucidated below.

\section{RESEARCH}

Four of seven sections of the communication skills course were asked to participate in focus groups concerning the group work workshops during the final class of the semester. Participation in these focus groups was voluntary and focus groups were conducted by researchers at McMaster's on campus institution for teaching and learning excellence, the MacPherson Institute. Data collected during these interviews were 
anonymized and returned to the instructor after the grades for the courses were submitted. The authors of this article obtained ethics approval for this research through McMaster's Research Ethics Board.

35 students chose to participate in the focus groups. There were five female participants and 30 male participants and all but one student (34) were in their firstyear of university. This demographic information is representative of the general make-up of the B.Tech. firstyear undergraduate program.

Student feedback highlighted the benefits of learning about group work in a low-stakes environment in which they identified learning about the process mattered more than the outcome of group tasks in the workshop. Students also noted that the group work workshops were a good way to get to know people and the activities helped them to become better group members.

Further, when asked to describe the greatest benefit to collaborating with peers or when asked to give advice to incoming first-year undergraduates about teamwork, students identified diversity in opinions and teammates as an important feature. The following excerpts are taken from the focus group in response to giving advice about groupwork to future B.Tech. students.

Table 1: Student Advice about Teamwork to Incoming First-Year Undergraduates

\begin{tabular}{|c|}
\hline $\begin{array}{l}\text { other people and trust their } \\
\text { ojects. }\end{array}$ \\
\hline $\begin{array}{l}\text { Response 2: Open oneself to diverse thinking methods- } \\
\text { Expose yourself to different perspectives learning to be } \\
\text { more tolerant of others. }\end{array}$ \\
\hline $\begin{array}{l}\text { Response 3: Meeting people for the first time, you may } \\
\text { not know what their habits are. Don't instantly lash out } \\
\text { at person if they say something you don't like. Talk to } \\
\text { the person. }\end{array}$ \\
\hline $\begin{array}{l}\text { Response 4: Give and take and be open to others' } \\
\text { opinions. Sometimes there is a language barrier - } \\
\text { misinterpretation, misunderstanding, or } \\
\text { miscommunication. }\end{array}$ \\
\hline $\begin{array}{l}\text { Response 5: When working by yourself, you think you're } \\
\text { doing fine. When working in group, you get different } \\
\text { perspectives and feedback. [It is/was] interesting to } \\
\text { study how people interact with each other. [It gave] } \\
\text { insight into how you behave [when] in a group. }\end{array}$ \\
\hline
\end{tabular}

These excerpts were selected because they spoke specifically of tolerance, diversity, or getting to know a teammate beyond just their work habits - in a way that would align with one's demographic diversity. Other similar responses included 'being open to multiple perspectives', 'being adaptable', and 'coming in with an open mind'. It was these excerpts, the experiences of the first author as an instructor, and the feedback from the focus group facilitators which highlighted the importance of diversity as an underlying topic in these sessions. These connections are further discussed in the following section.

\section{DISCUSSION}

Engineering Education scholars have argued for the importance of teaching group work and group project management $[7,8,9,10,11]$. These workshops provided an opportunity to spend time in the classroom teaching best practices for group work using experiential learning activities. Through various in-class work and assessment pieces, student feedback demonstrated an appreciation for the opportunity to self-reflect on their role in a team. Further, there appeared a shift in the awareness and tolerance of the diversity found among group members which demonstrates a potential area for further investigation.

The authors of this paper argue that these workshops are a positive start toward developing a tolerance toward diversity among the student body, in addition to helping students become successful practitioners and skilled team members. The building of tolerance was only possible through self-reflection to understand that there are differences between one's own and other's world view. While this discussion centred primarily around team work and group project preferences, it is in line with discussions of other forms of student diversity.

In its current form, the distinction between identifying and accepting a peer's teamwork preferences as a means of building tolerance toward a peer's social identity (incorporating social, cultural, ethnic, religious, or sexual identity) needs further exploration. It is the opinion of the authors that more needs to be done to build first-year students' awareness, skills, and level of tolerance toward diversity.

It is the opinion of the authors that these group work workshops are the first step toward building group work skills and tolerance toward identity. According to the firstauthor's experience in the field of intercultural competency training and scholars in this field [23], such training must be iterative and returned to periodically over time. Therefore, the authors of this paper advocate that future communications or management courses integrate material designed to develop students' self-awareness, through selfreflective activities, and build tolerance toward diversity through implied and overt activities and assessments.

Such an endeavor would require buy-in and commitment at both a faculty and departmental level. As one example, McMaster University's Faculty of Engineering will integrate two courses into its curriculum in the near future: the first will focus on gender equity in engineering workplaces while the second, will feature diversity in Canadian workplaces.

Feedback from the B.Tech. communications course focus groups on specific activities will also be integrated into future iterations. Future group work workshops will 
include an additional activity that will focus more overtly on the aspect of individuals' personal identities and its role in group work activities. Future focus groups will ask specific questions about the role of these workshops and its ability to engender tolerance for ambiguity and diversity among team members.

\section{CONCLUSION}

In an attempt to address employers concerns for workready graduates, 'group work' workshops were integrated into first-year communication skills courses in the B.Tech. program. These workshops provided a low-stakes environment where undergraduate students learned about the best practices of team membership and group work as identified by leading scholars in the field of Engineering Education. The hope for these workshops was to better equip students for future group work activities by providing them easy-to-remember tools and accessible resources about working in a group. What the authors found was that first-year students also developed an appreciation for their peers' individual demographic diversity and, through self-reflection, developed a deeper level of self-awareness. These secondary outcomes open the conversation to the importance of learning about interpersonal skills and teamwork early in engineering education where Canadian engineering faculty continue to struggle to diversify both their student body and faculty. More research is needed to understand the potential connection between fostering a tolerance toward diversity within these workshops and in undergraduate engineering classrooms.

\section{Acknowledgements}

The authors would like to thank the researchers at McMaster's MacPherson Institute for their work in facilitating focus groups mentioned in this paper.

\section{References}

[1] Joanna Wolfe, Beth A Powell, Seth Schlisserman, and Alexandra Kirshon, "Teamwork in Engineering Undergraduate Classes: What Problems Do Students experience?," in ASEE Annual Conference \& Exposition, (New Orleans, Louisiana; 2629 June 2016), 2016.

[2] Penny L. Hirsch, and Ann F. McKenna. "Using reflection to promote teamwork understanding in engineering design education." International Journal of Engineering Education vol. 24, no. 2, pp. 377-385, 2008.

[3] Cynthia E. Foor, Susan E. Walden, and Deborah A. Trytten. " II Wish that I Belonged More in this Whole Engineering Group': Achieving Individual Diversity." Journal of Engineering Education, vol. 96, no. 2, pp. 103, 2007.
[4] Engineers Canada, Canadian Engineers for Tomorrow: Trends in Engineering Enrolment and Degrees Awarded 20072011, Ottawa, Canada: Engineers Canada (December 2012), https://engineerscanada.ca/sites/default/files/w_report_enrolmen t_eng.pdf.

[5] Ann B. Denis, and Ruby Heap. "Social Relevance and Interdisciplinarity in Canadian Engineering Education." GIEE 2011: Gender and Interdisciplinary Education for Engineers. Sense Publishers, pp. 255-266, 2012.

[6] ONWIE (Internet), Percentage of Female Undergraduates in Engineering (Canada), http://www.onwie.ca/resourcestools/statistics/percentage-of-female-undergraduates-inengineering-canada-

[7] Barbara A. Oakley, Darrin M. Hanna, Zenon Kuzmyn, and Richard M. Felder. "Best practices involving teamwork in the classroom: Results from a survey of 6435 engineering student respondents." IEEE Transactions on Education, vol. 50, no. 3 pp. 266-272, 2007.

[8] Richard M. Felder, and Rebecca Brent. "Effective strategies for cooperative learning." Journal of Cooperation \& Collaboration in College Teaching vol. 10, no. 2, pp. 69-75, 2001.

[9] Karl A. Smith, Sheri D. Sheppard, David W. Johnson, and Roger T. Johnson. "Pedagogies of engagement: Classroom-based practices." Journal of engineering education, vol. 94, no. 1, pp. 87-101, 2005.

[10] Cynthia J. Finelli, Inger Bergom, and Vilma Mesa. "Student teams in the engineering classroom and beyond: Setting up students for success." CRLT Occasional Papers, no. 29, pp. 1-12, 2011.

[11] Barbara Oakley, Richard M. Felder, Rebecca Brent, and Imad Elhajj. "Turning student groups into effective teams." Journal of student centered learning, vol. 2, no. 1, pp. 9-34, 2004.

[12] Charles Duhigg, "What Google learned from its quest to build the perfect team." The New York Times Magazine, Feb. 25, 2016.

[13] Erik De Graaf, and Anette Kolmos. "Characteristics of problem-based learning." International Journal of Engineering Education, vol. 19, no. 5, pp. 657-662, 2003.

[14] Joseph Luft, and Harry Ingham. "The Johari Window: A graphic model for interpersonal relation." Proceedings of the Western Training Laboratory in Group Development, University of Georgia, Los Angeles, Extension Office, 1955. 
[15] Robin S. Adams, Jennifer Turns, and Cynthia J. Atman. "Educating effective engineering designers: The role of reflective practice." Design studies, vol. 24, no. 3, pp. 275-294, 2003.

[16] Karen Mann, Jill Gordon, and Anna MacLeod. "Reflection and reflective practice in health professions education: a systematic review." Advances in health sciences education, vol. 14, no. 4, pp. 595, 2009.

[17] Julia M. Williams, "The engineering portfolio: Communication, reflection, and student learning outcomes assessment." International Journal of Engineering Education, vol. 18, no. 2, pp. 199-207, 2002.

[18] Jonathan Hey, Alan Van Pelt, Alice Agogino, and Sara Beckman. "Self-reflection: Lessons learned in a new product development class." Journal of Mechanical Design, vol. 129, no. 7, pp. 668-676, 2007.

[19] Mezirow Jack, "Fostering Critical Reflection in Adulthood." 1990.

[20] Margaret Neale, Stanford GSB Staff, "Diversity and Work Group Performance." Stanford Graduate School of Business. 1999 from https://www.gsb.stanford.edu/insights/diversitywork-group-performance.

[21] Karen A. Jehn, Gregory B. Northcraft, and Margaret A. Neale. "Why differences make a difference: A field study of diversity, conflict and performance in workgroups." Administrative science quarterly, vol. 44, no. 4, pp. 741-763, 1999.

[22] Richard H. Robbins, Maggie Cummings, and Karen McGarry, Sociocultural Anthropology: A Problem-Based Approach. Nelson Education Limited, 2016. \{ISBN: 978-017657016-3\}

[23] Duan-Ying Cai. "A concept analysis of cultural competence" International Journal of Nursing Sciences, vol. 3, no. 3, pp. 268273, 2016. 